\title{
Editorial
}

\section{Are Biological Systems Social Systems?}

There have been discussions raging over the centuries if and whether at least some social systems are biological, organic and spontaneous. Are they alive or, at least, do they behave as if they were alive? Or, are they just man-made machines, contrivances and artifacts?

Now we are ready to complete the argument: not only there are some spontaneous, self-producing (i.e., autopoietic) social systems, but also: all autopoietic systems (including biological) are necessarily social systems.

In other words, living organisms, neural systems, living cells, etc., in order to be living and therefore self-producing, must be necessarily social. One can even form a conjecture: all self-producing (autopoietic) systems are social, including the self-producing social systems themselves.

Not all social systems (and not all natural systems) are self-producing. Man-made, artificially contrived social constructs do not produce themselves and are held together by force. The test is simple: if major restrictions, "walls" and enforcements are removed, does the system disintegrate or does it grow and strengthen?

"Social" systems, in spite of all their metaphoric and antropomorphic meaning and intuitions, are characterized by coordination (or harmony) of individual action achieved through communication among individuals. So, a group of fish thrown together by a tide wave is a passive aggregation, not a social system. A swarm of moths lured to a porch light is an active aggregation, not a social system. A flag-pattern of athletes achieved through bullhorn commands shouted from the center is a purposeful aggregation, not a social system. Mere interaction of components is not sufficient: billiard

IOS Press

Human Systems Management 10 (1991) 79-81 balls interact and so do grains of sand - nobody would call them social systems. "Cooperation" is not precise or sufficient either: it is also the "competition" of individuals from which their social "coordination" emerges.

Jim Michaelson of Harvard is one of the first biologists who are prepared to treat biological systems as social systems: The "competition" of cells, the selection and survival of the most "fit" during embryonic development, is dependent on cell's ability to secrete enzymes, its rates of proliferation, etc. This is a far cry from the deterministic and essentially "non-biological" dogma that (somehow) the growth of an organ is genetically programmed into the cells which then go through an exquisitely precise and harmonious series of events.

All physical, biological and higher autopoietic organizations are component systems that produce and reduce their own basic components: they are self-producing, self-modifying and self-renewing.

Social system is therefore a network of interactions, reactions and processes involving:

1) production (poiesis): the rules and regulations guiding the entry of new living components (such as birth, membership, acceptance);

2) bonding (linkage): the rules guiding associations, functions and positions of individuals during their tenure within the organization.

3) degradation (disintegration): processes associated with the termination of membership (death, separation, expulsion).

In Fig. 1 we graphically represent the above three poietic processes and interconnect them into a cycle of self-production.

In Fig. 1 observe that all circularly concatenated processes represent "productions" of components necessary for other processes, not only the one designated Production. To emphasize this crucial 


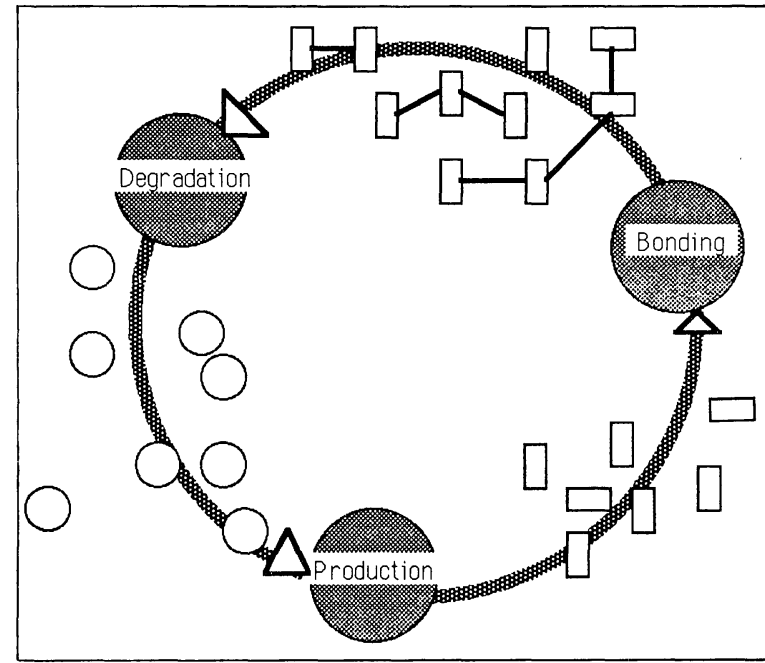

Fig. 1. Circular organization of interdependent processes and their "productions".

point we speak of poiesis instead of production and autopoiesis instead of self-production. Although in reality hundreds of processes can be so interconnected, the above three-process model represents the minimum conditions necessary for autopoiesis to emerge.

From the vantage point of Fig. 1, Zeleny and Hufford [6] argue that all biological (autopoietic) systems are social systems. They consist of production, linkage and disintegration of interrelated components and components-producing processes. An organism or a cell are therefore social systems. Without the understanding the poiesis of their components, we cannot even hope to understand them as wholes.

Von Hayek [3] has been one of the first and most influential proponents of spontaneous (or "extended") social orders. It is interesting to quote from his recent work:

"When I began my work I felt that I was nearly alone in working on the evolutionary formation of such highly complex self-maintaining orders. Meanwhile, researchers on this kind of problem under various names, such as autopoiesis, cybernetics, homeostasis, spontaneous order, selforganization, synergetics, systems theory, and so on - have become so numerous ..."

There is a little known collection of essays edited by Howard Topoff [5]. He writes, as a matter of fact and simple intuition,
"What do human beings, ants, and slime have in common? Despite their vast differences in structure, physiology and ecology, all three consist of individuals whose behavior is sufficiently coordinated for the group to be called a society."

The main question is as follows: Is this "coordination" and the resulting society due to executing a preconceived plan of a social engineer, central planner or a great designer (like in heteropoietic systems), or is it due to the distributed unintended self-coordination of individually goal-seeking and autonomously behaving individuals (like in autopoietic systems)?

Slime molds is an excellent example of autopoietic social systems, described also by Garfinkel [2]. Amoebas are individual cells moving around in search for bacteria to eat. Often they eat so much and produce new amoebas so rapidly that their food supply has no chance to replenish itself. In times of food scarcity they move rapidly to a central point, collecting themselves in a well differentiated spontaneous aggregation (center cells, boundary cells, etc.).

The group then assumes the shape of a "slug", with a head, tail and a "purpose": searching collectively for a new source of food. The changing of the roles of individual amoebas is required: the original leaders who formed the center of attraction are dispersed throughout the "slug", and new leaders emerge, forming the goal-seeking head.

The head of the home-hunting "slug" are simply the fastest-moving amoebas. The "slug" is just a spontaneous temporary metaorganism, maintaining each amoeba as a complete individual. Once the leaders locate a new source of food, they change quickly from the first to the last: they form the base of a stalk which follower-amoebas continue to build up into a mushroom-like metaorganism. At its top, hundreds of thousands of amoebas turn into small dry spores and, after the mushroom "head" bursts, disperse to new and potentially nourishing environments. When they fall to earth, they change once again into the individual amoebas which reproduce by cell division. This ecological cycle is then repeated.

Marvin Minsky has titled his recent book The Society of Mind [4], attempting to exploit the social metaphor for characterization of biological sys- 
tems. Minsky's "society" is still the hierarchy of "agents" (or experts), based on the extreme division of labor: each of them doing "some simple thing that needs no mind or thought at all.', Minsky is a social engineer of command systems, with little or no awareness of social systems, but he did make a small step by calling biological systems (mind included) societies.

Edelman [1] does improve upon Minsky by stating:

"Any satisfactory developmental theory of higher brain function must remove the need for homunculi and electricians at any level and at the same time must account for object definition and generalization from a world whose events and "objects" are not prelabeled by any a priori scheme or top-down order."

There is now a journal called Social and Biological Structures, edited by Paul Levinson, concerned with: "the unity, analogy, and relationships between biological dynamics and mechanisms and social activities." People around that journal include Elias L. Khalil, Harlan Cleveland, Murray Turoff or Donald T. Campbell.

Kenneth Boulding is preparing a book with E. Khalil on Social and Natural Complexity, with contributors like Peter Allen ("Life Beyond Newtonian Paradigm"'), Henri Laborit ("Biological Basis of Social Behavior"'), John. H. Campbell and Gregory B. Stock ("A Biological Interpretation of Human Society as an Emerging Superorganism: Implications for Public Policy'), Robert Rosen, Ramon Margalef, Stuart Kauffman, Michael Rothschild, and others.
Let us conclude with words of von Hayek [3]:

"To the naive mind that can conceive of order only as the product of deliberate action, it may seem absurd that in complex conditions order, and adaptation to the unknown, can be achieved more effectively by decentralising decisions, and that division of authority will actually extend the possibility of overall order."

\section{References}

[1] G.M. Edelman, Topobiology, Basic Books, New York, 1988.

[2] A. Garfinkel, "The Slime Mold Dictyostelium as a Model of Self-Organization in Social Systems," in: Self-Organizing Systems: The Emergence of Order, edited by F. Eugene Yates, Plenum Press, New York, 1987, pp. 181-212.

[3] F.A. Hayek, The Fatal Conceit, University of Chicago Press, Chicago, 1988.

[4] M. Minsky, The Society of Mind, Simon and Schuster, New York, 1986.

[5] H. Topoff (ed.), Animal Societies and Evolution, W.H. Freeman \& Co., San Francisco, CA, 1981.

[6] M. Zeleny and K.D. Hufford, "The application of autopoiesis in systems analysis: Are autopoietic systems also social systems?' International Journal of General Systems, 1991 (to appear ).

[7] M. Zeleny, "'Spontaneous Social Orders,", in: A Science of Goal Formulation: American and Soviet Discussions of Cybernetics and Systems Theory, edited by S.A. Umpleby and V.N. Sadovsky, Hemisphere Publishing Corp., Washington, D.C., 1991, pp. 133-150.

Milan ZELENY

Graduate School of Business Fordham University at Lincoln Center New York, NY 10023

USA 